\title{
Sharing Building Information using the IFC Data Model for FDS Fire Simulation
}

\author{
${ }^{1}$ JOHANNES DIMYADI, ${ }^{2}$ MICHAEL SPEARPOINT and ${ }^{3}$ ROBERT AMOR \\ ${ }^{1}$ Facilities Management \\ Unitec New Zealand, New Zealand \\ ${ }^{2}$ Department of Civil and Natural Resources Engineering \\ University of Canterbury, New Zealand \\ ${ }^{3}$ Department of Computer Science \\ University of Auckland, New Zealand
}

\begin{abstract}
This paper describes part of a research project that looks into the potential and challenge of using the Industry Foundation Classes (IFC) open standard building information model in fire engineering design. In particular the paper describes work undertaken to share building geometry and other information with the Fire Dynamics Simulator (FDS) fire simulation model. A commercially available building information modeling (BIM) authoring application has been used to create building geometries and export IFC data files. A web-based conversion tool has been created to generate FDS input data given the output from a dedicated fire engineering IFC parser tool. The capabilities and outcome of data sharing process is illustrated in this paper using a simple test case building.
\end{abstract}

KEYWORDS: modelling, industry foundation classes, digital data sharing

\section{INTRODUCTION}

Getting an accurate building geometry is a basic and essential requirement for any fire simulation model, yet this can often be a challenging process. The conventional paper-based approach to transfer building information from printed drawings to computer software applications for engineering analyses has been shown to be inefficient and error prone. A study by NIST in 2004 reported a $\$ 15.8$ billion annual cost to the US capital facilities industry as a consequence of inadequate interoperability due to the "highly fragmented nature of the industry, the industry's continued paper-based business practices, a lack of standardization, and inconsistent technology adoption among stakeholders” [1].

There has been a growing trend in the Architectural, Engineering, Construction / Facilities Management (AEC/FM) industry to use building information modelling (BIM) tools, which are new generation objectbased CAD software applications capable of constructing and assembling building elements in a virtual environment. The BIM data produced by these tools comes in various formats. Most of these data formats are proprietary due to their commercial nature although they have varying degrees of accessibility depending on whether the data model specifications are available.

There are several non-proprietary building data models currently available. One of these is the Industry Foundation Classes (IFC), an open standard data model developed by the International Alliance for Interoperability (IAI), which was formed in 1995 by an international consortium of organisations in the AEC/FM industry. The IFC data model allows the building geometry and materials property information to be exported from a BIM authoring tool to a standard format such as the IFC compliant STEP (Standard for Exchange of Product Model Data) physical data file [2].

An example of current practice of IFC based BIM data sharing includes the Building and Construction Authority of Singapore, which accepts IFC-compliant building consent applications by electronic submission for code compliance checking. A similar effort is currently being implemented in the US by the International Code Council (ICC) in the Automated Code Compliance Checking (AC3) project [3].

\section{IFC AND STEP}

IFC is a standardised non-proprietary data model which has started to be adopted as an international interoperability standard for sharing building information within the AEC/FM community. The current IFC2x3 version of the model contains 653 building entities and over 300 supplementary data types as well 
as 'extensible property sets' [4]. The work described here uses the previous IFC2x2 release since entities of interest have not changed between the IFC2x2 and IFC2x3 releases and this adoption maintained compatibility with earlier research.

The IFC data model is essentially constructed in a hierarchical structure. However, its object-oriented design allows complex relationships to exist between entities. Entities may be physical objects such as doors, windows, walls etc. or more conceptual entities such as spaces or processes, contractual details etc. The data model structure is often represented using the EXPRESS-G notation, a graphical modelling language subset of EXPRESS [5] used for identifying model classes, data attributes and their relationships. Figure 1 shows part of the IFC model structure in EXPRESS-G displaying main building elements.

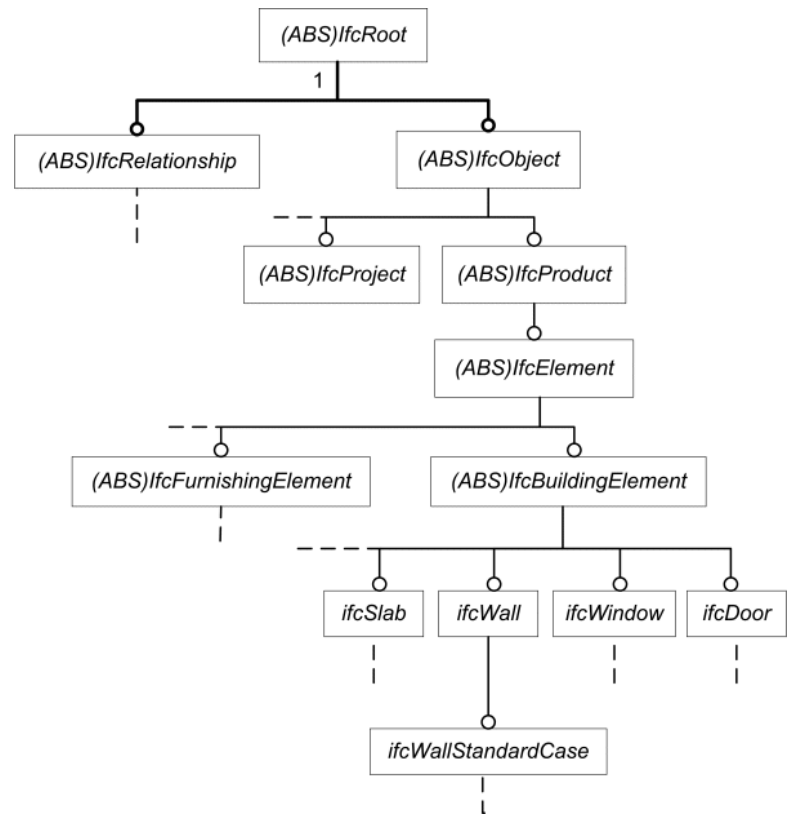

Fig. 1. EXPRESS-G diagram showing part of the IFC model structure (other details omitted for brevity).

Currently the most common method of data exchange between IFC compliant software applications is by using the STEP physical file (SPF). SPF is defined in ISO 10303-21:2002 Clear Text Encoding of the Exchange Structure [2] in a text format containing human readable ASCII characters (Fig. 2). The size of a SPF is usually quite large. For example, a simple two room test model would contain as many as 10,000 lines of data.

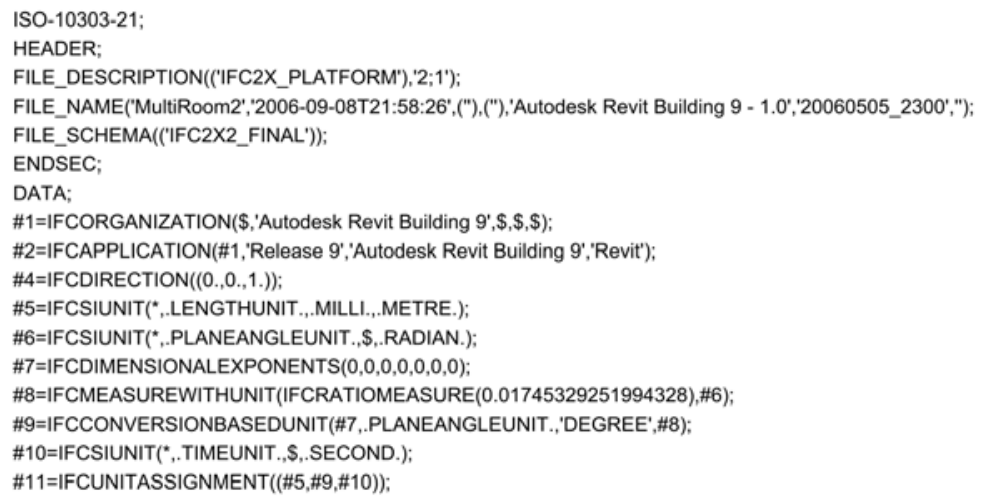

Fig. 2. An extract from a STEP physical file.

Several stand-alone software utilities are available to read and navigate SPF as well as for visualising the model. Object model servers and software components are also available to navigate SPF programmatically for use in application development. 
As an alternative method to SPF, IFC data can also be exchanged by using the ifcXML representation (ISO 10303-28:2003), which was made available to take advantage of the XML technology [6].

The IFC Model is ideally suited to meet the requirements set out by Mowrer et al. [7] for room fire modelling where the object-oriented structure and the ability to associate properties to objects were two of the key points identified.

\section{CAD AND BIM}

Although Computer Aided Design (CAD) has been used for almost half of a century as an electronic drafting tool, the mass adoption by the AEC/FM industry only started in the early 1980s following the release of commercial CAD products on PC computers.

Conventional CAD systems come in 2D drafting and 3D modelling environments. The representation of 3D objects can be achieved by either surface or solid modelling. Surface modelling is most useful in the creation of open freeform surfaces and objects with complex shapes. In surface modelling, 3D geometrically closed objects are created by defining the shell of the boundary surfaces enclosing the volume of the objects. This technique focuses on the accurate geometric representation of the object rather than concerns about its physical properties. The common entities identified with 3D surface modelling in commercial CAD applications are POLYFACE, REGION, 3DMESH and 3DFACE.

Solid modelling may be a more appropriate technique in representing 3D objects in a building modelling application particularly when the physical properties of the objects are relevant. Editing of solids is achieved by Boolean operations such as union, subtract, and intersect, etc. One of the most common entity type encountered with solid modelling in commercial CAD applications is 3DSOLID.

For the past decade, the AEC/FM industry specific CAD technology has evolved into the new generation object-based BIM concept. BIM is intended to integrate all information related to the building from design through to construction and facilities management in one virtual data model that can be maintained throughout the entire life-cycle of the building. The working definition of BIM as originally developed by the Facilities Information Council of the US National Institute of Building Sciences is "A computable representation of the physical and functional characteristics of a facility and its related project/life-cycle information using open industry standards to inform business decision making for realizing better value. BIM can integrate all the relevant aspects into a coherent organization of data that computer applications can access, modify and/or add to, if authorized to do so" [8].

In the BIM environment, a solid object represents a virtual building block with a set of properties that can be assembled into a larger composite object. Objects have a defined placement relative to other objects within the environment and may have relationships with each other. Editing or moving one object may affect the properties or placement of other objects.

In this work, Autodesk's Revit Building 9 was used as the BIM authoring tool to construct a range of test case building models. The corresponding IFC conforming SPF of the building models were obtained using the data export feature of that application.

\section{INFORMATION EXCHANGE FOR FIRE ENGINEERING APPLICATIONS}

The principal designer of a building is usually an architect, a building engineer, a structural engineer, or an architectural designer. It is very seldom that a fire engineer or a building services engineer assumes the role of the principal designer of the building.

Conventionally a fire engineer would be given a set of printed drawings or CAD files from the principal designer of the building. The required information would then be manually collated or extracted from these sources for use in the code compliance assessments and for carrying out engineering analysis. In the absence of a CAD file, the fire engineer may choose to reconstruct the building model in a CAD environment using the information gathered from the printed drawings for the purposes of sharing the output data with fire simulation applications. 
One of the most commonly used CAD output formats for this purpose is DXF, which is supported by a number of fire simulation applications, although with varying degrees of success depending on which CAD application is used to export the data. Formats such as DXF generally require that the original files be manually 'cleaned' of data that would otherwise be incorrectly interpreted by the intended simulation software and limitations mean that only basic geometric primitives can be derived because more detailed definitions of objects cannot be included.

\section{BIM for fire engineering applications}

As BIM is gaining popularity in building design, it would soon be possible for a fire engineer to obtain a working copy of the building model or the IFC output file instead of the paper drawings or conventional CAD files. There are a number of scenarios in which this new form of information could be used in fire engineering design:

1. A SPF can be imported into a BIM authoring/editing application in which the building model can be studied in detail in preparation for a preliminary assessment of the building from the fire engineering perspective.

2. Using the modelling or editing tools in the BIM application, the fire engineer may be able to make simplifications to the building or add certain elements and properties to the model in order to create a fire scenario to be analysed or simulated. The result may be exported as a revised SPF.

3. The revised SPF may be parsed by a fire engineering specific tool to generate the input data required by one or more fire simulation software applications using interfaces developed specifically for this purpose.

4. The generated input data for the fire simulations can be further edited, if required, using any dedicated software interfaces developed specifically for a particular fire simulation application.

5. Any recommended modifications or additions to the building as the result of the fire engineering assessment may be highlighted or incorporated into the model using a BIM authoring tool. For example, the fire rating of a door may be changed in the building model, or new fire engineering properties may be added to the building model as appropriate. The result may be communicated to the principal designer in the form of a SPF, from which the revised elements or new properties could be extracted and incorporated into the master BIM.

The above scenarios assume that software applications have adopted a common BIM standard and have implemented standardised IFC-based data interoperability methods to guarantee the integrity of the information exchanged. Recent studies have shown that there are still issues associated with two-way sharing of building model information. The main issues relate to the level of compliance with the data interoperability standards being adopted by various software implementations and the inherent complexity of the current IFC model [9].

This paper shows how the sharing of building information between CAD/BIM and the Fire Dynamics Simulator (FDS) fire simulation model [10] can be achieved and incorporated with other data manipulation tools. For illustration purposes, an example building has been selected from a set of trial models used in the research. The selected building model was created in Revit Building 9 and exported as an IFC2x2 SPF. This file was then processed using a specifically developed parser tool to extract the geometrical information and this information then used to create an FDS input file. The generated FDS input file was further edited using a commercially available software package. The edited FDS input file was finally used to execute a simulation run and the results viewed in a graphical output environment. FDS 4.0.7 was used for this work as it was current at the time of the research.

\section{Phase 1: Building creation}

A simple trial building (Fig. 3) was created in Revit Building 9 consisting of two different size rooms, the larger having approximately twice the floor area of the smaller. Two doorways to the outside were placed, one opening outward from the larger room and the other inward into the smaller room. Two windows were also placed, one to the outside from the larger room and another internally between the two rooms. The walls were all $2.4 \mathrm{~m}$ tall and $100 \mathrm{~mm}$ thick single layer of 'common brick'. A $150 \mathrm{~mm}$ thick flat slab entity 
was placed at floor and ceiling levels. A box object was also placed in the centre of the smaller room representing a piece of furniture or a group of furniture items that might be the source of a fire. The building was not created for architectural considerations but is sufficient to test the geometrical conversion to FDS.

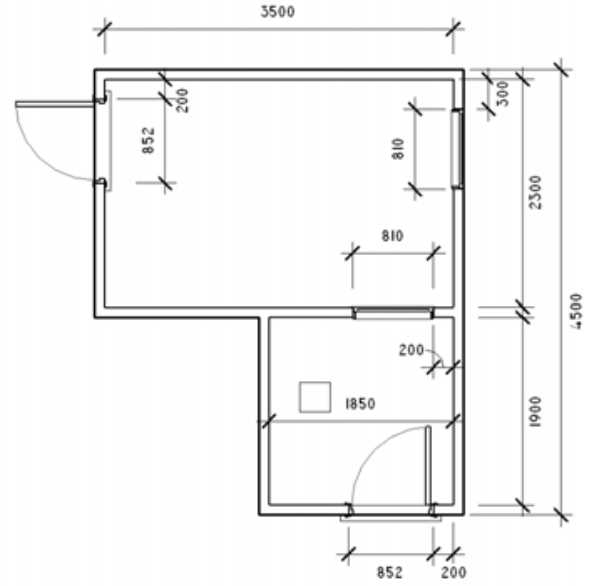

(a)

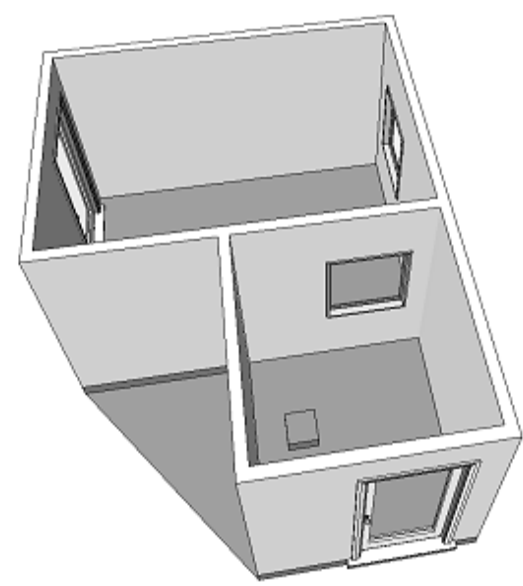

(b)

Fig. 3. Demonstration two-room building created in Revit Building 9:

(a) Plan view (with dimensions in $\mathrm{mm}$ ); (b) Perspective view

\section{Phase 2: Geometrical processing}

It is assumed that readers are familiar with zone and field modelling concepts and also with computer fire simulation tools such as BRANZFIRE [11] and FDS. The ability to share a common building information model between design and engineering analysis software applications depends on how successfully the data can be mapped from one schema to the other. The building geometry information required by FDS as input is quite different to those required by zone model applications and these differences are discussed elsewhere [12].

For FDS, a software utility DXF2FDS developed by Sheppard [13] can be used to extract 3DFACE entities from DXF files created by CAD applications and generates FDS version 4 compatible obstruction block data. To use this utility, a building model must be constructed entirely of 3DFACE objects, which are not widely supported. Current commercial CAD applications offer 3D solid modelling as a more efficient method for constructing building models. In order to share the DXF file of a building model constructed with 3DSOLID, a separate conversion process would be necessary.

The properties of 3DSOLID objects are often not easily accessible due to the proprietary nature of CAD systems. However, a technique has been used successfully in the Autodesk's AutoCAD environment to extract the coordinates of 3DSOLID entities directly. The technique involves querying the drawing database programmatically using the LISP programming language and extracting the bounding box coordinates for all the 3DSOLID entities found, and then writing these data to a text file as properly formatted \&OBST lines for FDS. This has been developed into 3DSOLID2FDS add-on for AutoCAD and is freely available as a third-party tool from the official FDS web site.

An IFC-based STEP parser software tool has been under development at the University of Canterbury in New Zealand for the past few years [14]. The tool has been developed as a filter to extract a subset of relevant entities from the STEP output of a building model for use in fire engineering applications (Fig. 5). Due to the complexity of the SPF, an ActiveX software component [15] was used in this work to assist with the interrogation process of the IFC file. The tool was initially developed to map a limited set of IFC entities sufficient for generating the input data required by zone model applications such as BRANZFIRE. The parser takes as input the SPF of the building model exported from a BIM authoring tool and generates an XML document containing the geometrical and other information of the model. 
As part of this research project, the scope of the ifcSTEP Parser was further developed and extended to incorporate walls and wall openings with their absolute positioning coordinates as required by FDS. A furniture item or a group of fuel packages represented by a box can also be exchanged if the objects were found in the original building model. Further details about this development work and the geometrical exchange process are presented elsewhere [16, 17].

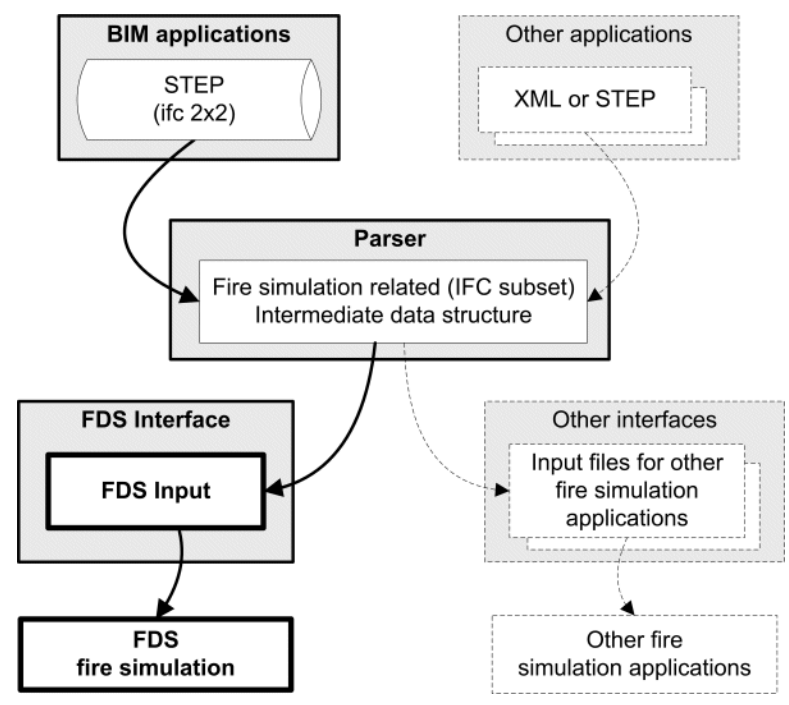

Fig. 4. Data exchange process.

As the result of this work, the ifcSTEP parser has now been revised to incorporate a new set of information required for mapping essential building information to FDS. However, the current scope of the data mapping filter is still somewhat limited. The main limitations can be summarised as follows:

- No support for Boundary Representation (BREP) geometry, which is the common default representation in IFC model output for objects with geometry that cannot be resolved using parametric solids.

- Only straight, orthogonal and equal height walls can be mapped. Methods to parse diagonal, inclined and curved surfaces have not been implemented.

- Mapping of building elements are limited to standard walls, vertical wall openings such as doors and windows, roof and floor slabs. Stair elements and horizontal openings in floors and roofs are not supported.

- IFC property sets are not supported which limits the mapping of properties to only those already hard-coded as attributes in the building model. The support of property sets may allow other more specific properties such as the heat release rates of fire, species yields, heat of combustion, etc. to be attached to the model and exchanged like any other attributes.

- Mapping of a furniture item or a group of fuel-packages is limited to the placement coordinates of a box representation with predetermined dimensions.

\section{Phase 3: Input file creation}

A web-based conversion tool was developed as part of the research and was written in HTML with embedded PHP code. The application is commercially hosted but freely available for access on the internet [16]. The input required by ifcSTEP-FDS is an XML document containing the building geometry as generated by the ifcSTEP Parser. The conversion tool has four main output features, i.e. to display the content of the XML document, a brief summary of the mapping results, the graphical display of the building plan view, and the generated FDS input data (Fig. 5). 


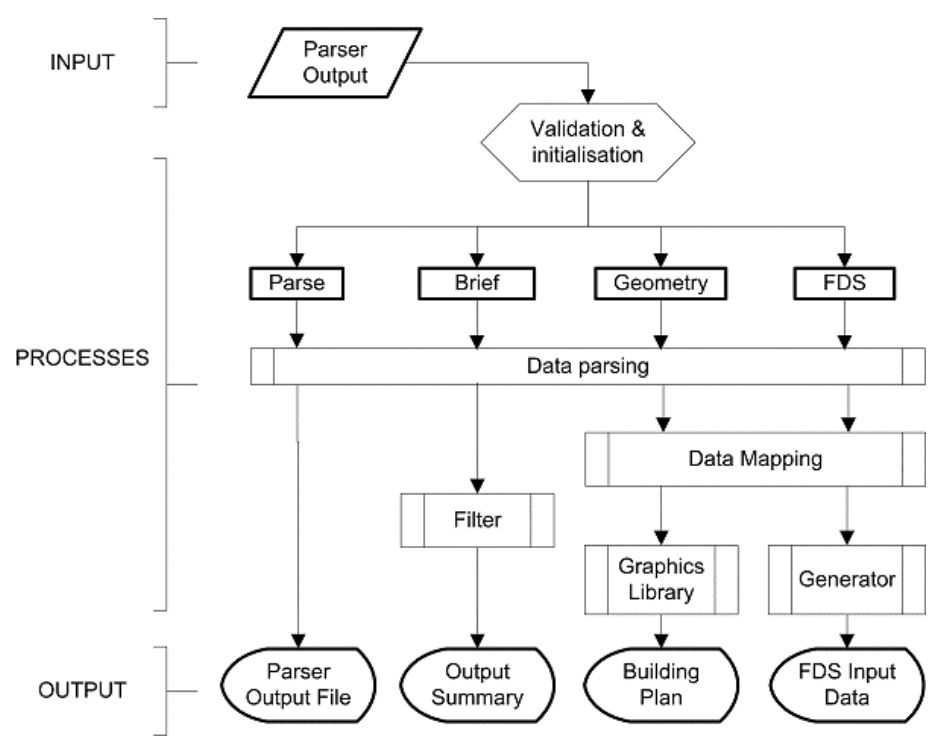

Fig. 5. ifcSTEP-FDS application flow diagram.

Figure 6 shows screenshots of the graphical display of the model plan view with tabulated coordinates for each wall and wall openings, and the generated FDS input data, respectively. The graphical display of the model is intended as a preview to visually verify the mapping of walls and wall openings. The on-screen display of the generated FDS input data can be copied to the clip-board for transfer to a text file.

Apart from the limitations inherited from ifcSTEP Parser, there are specific limitations to the ifcSTEP-FDS conversion tool, as follows:

- No other data import facilities have been implemented. The only acceptable input to the conversion tool is the XML document generated by ifcSTEP Parser.

- $\quad$ No algorithms for stair-stepping of diagonal, inclined and curved surfaces have been implemented as only straight and orthogonal wall elements can currently be mapped by the ifcSTEP Parser.

- $\quad$ Only 2D building plan geometry display is currently supported.

- The generation of FDS input data has the emphasis on the transfer of the building geometry and the setup of the computational mesh. No user interface has been implemented to allow other FDS input parameters to be entered separately, however a set of basic essential parameters with default values are included in the output.

Apart from the wall obstructions and wall openings, there are also several other predefined parameters included in the generated FDS input data. There are two predefined fire growth descriptions included, namely 'Fire_Steady' and 'Fire_Growing'. In both cases, the initial Heat Release Rates per Unit Area (HRRPUA) specified is $2000 \mathrm{~kW} / \mathrm{m}^{2}$ and the growing fire parameter is defined by a simple ramping function. Three types of surface material definition and properties are included. The bottom computational domain boundary plane has conveniently been defined as having 'CARPET' surface material. Similarly, the top boundary plane has been defined to have 'PAINTED_GIB' surface material. The 'UPHOLSTERY' material can be used to attach to fuel packages. The 'CARPET' and 'UPHOLSTERY' properties were taken from the FDS 4 database, and the 'PAINTED_GIB' is based on Eurefic cone calorimeter tests [11]. These predefined parameters are included by default for convenience and should normally be edited to suit prior to the fire simulation. 


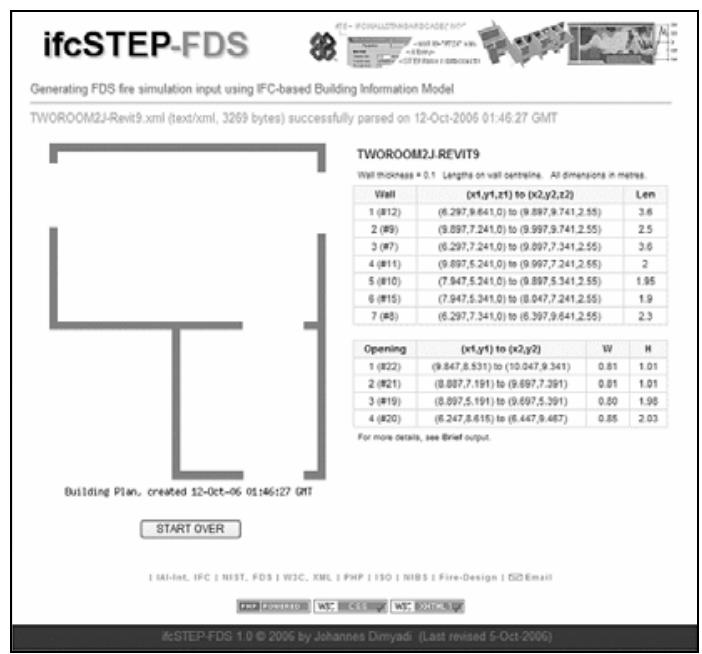

(a)

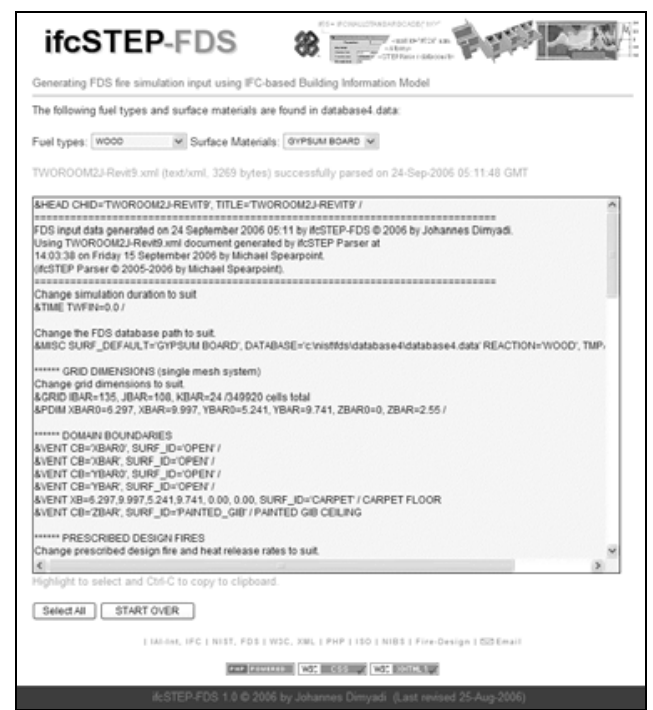

(b)

Fig. 6. Screenshots of ifcSTEP-FDS output: (a) graphical view of model; (b) FDS input generated.

Figure 7 shows an extract of the FDS 4 compatible input data generated from the original version of ifcSTEP-FDS and illustrates the successful conversion of the original geometry encapsulated in the original BIM representation (Fig. 3). The seven wall elements have been correctly sized and positioned using the \&OBST instruction. The four door and window openings have been likewise included using the \&HOLE instruction. The conversion process assumes that all doors and windows provide an unrestricted opening through its parent boundary element.

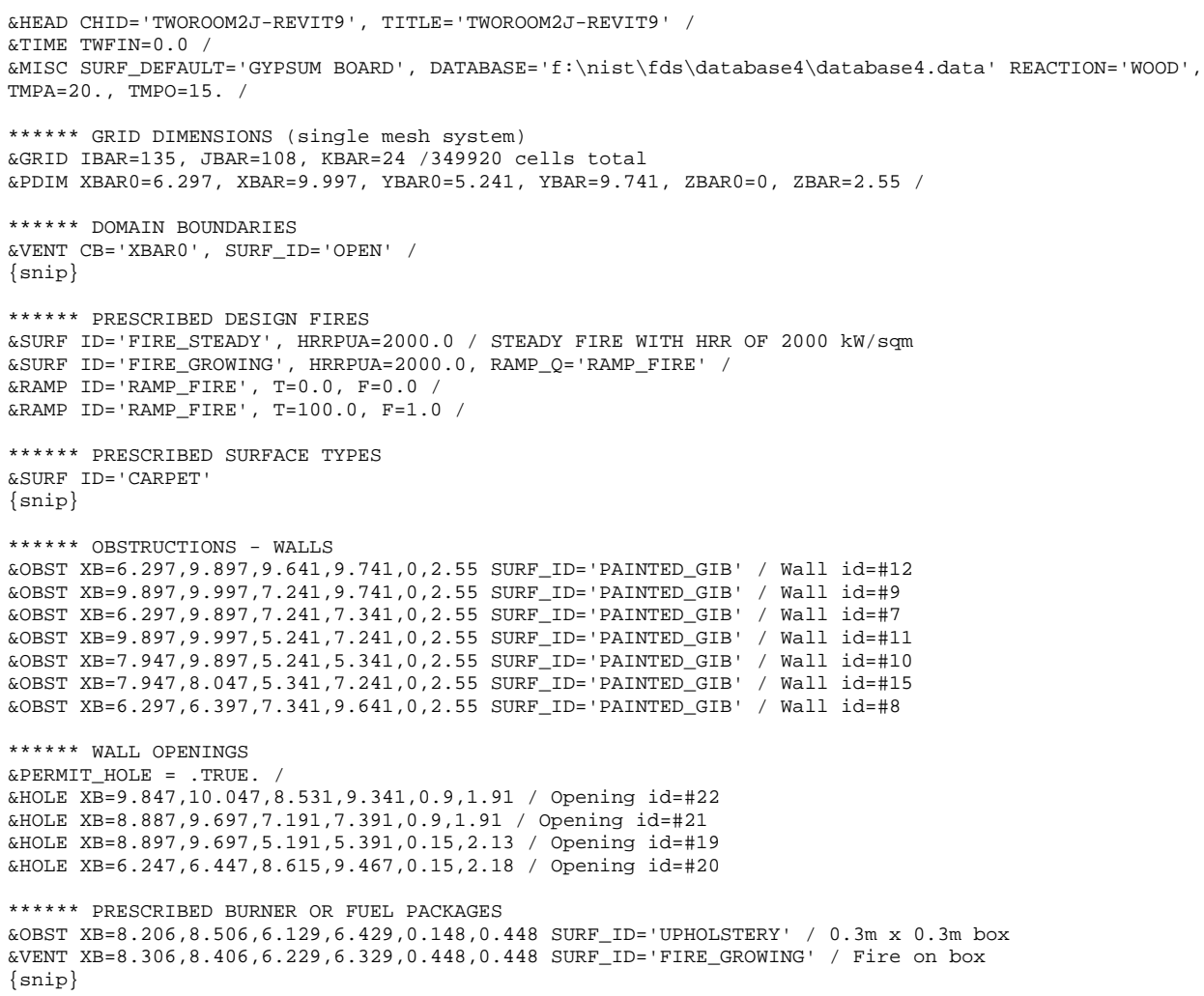

Fig. 7. Generated FDS 4 input data with details omitted for brevity shown by $\{$ snip\}. 


\section{Phase 4: Input file editing}

Further editing of a fire simulation input file can often be carried out using a simple text editor however this can be quite a laborious process. Instead it is usually more efficient to use a graphical user interface (GUI) application specifically designed for the fire simulation tool.

For FDS, for example, there is a commercial software application called PyroSim released by Thunderhead Engineering [18]. This is a stand-alone GUI software application that can be used to construct, read and edit FDS input files. PyroSim has many useful features to enable the visual creation and editing of FDS input files and supports all of the input namelist groups available in the current version of FDS. It also allows FDS and Smokeview files to be directly executed from within the application.

The current version of PyroSim does not support IFC import or export directly. However, it can be used to import the FDS input file generated by ifcSTEP-FDS for further editing before running the simulation. Fig. 8 shows the generated FDS input file for the test case building being edited in PyroSim.

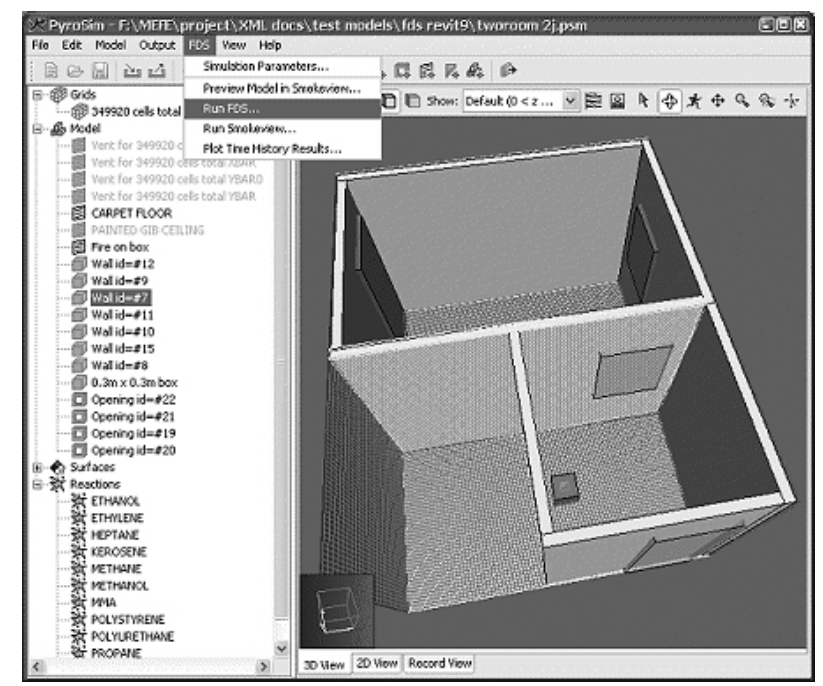

Fig. 8. FDS input file for a test case building being edited in Pyrosim.

\section{Phase 5: Execution and visualisation}

The final phase of the process is to execute the simulation and view the results using the SmokeView software that comes as part of the FDS installation package. FDS users will be familiar with this process and so it is not detailed here.

Once transferred and saved as an external file, the generated FDS input data can be fed immediately into FDS. As the default duration of the simulation is set to zero in the input file, the result of the simulation would initially be the SmokeView file containing the building geometry, which can be used to preview and verify the model (Fig. 9a). Results of executing the predefined fire growth descriptions exported from the ifcSTEP-FDS tool are illustrated in Fig. 9b. 

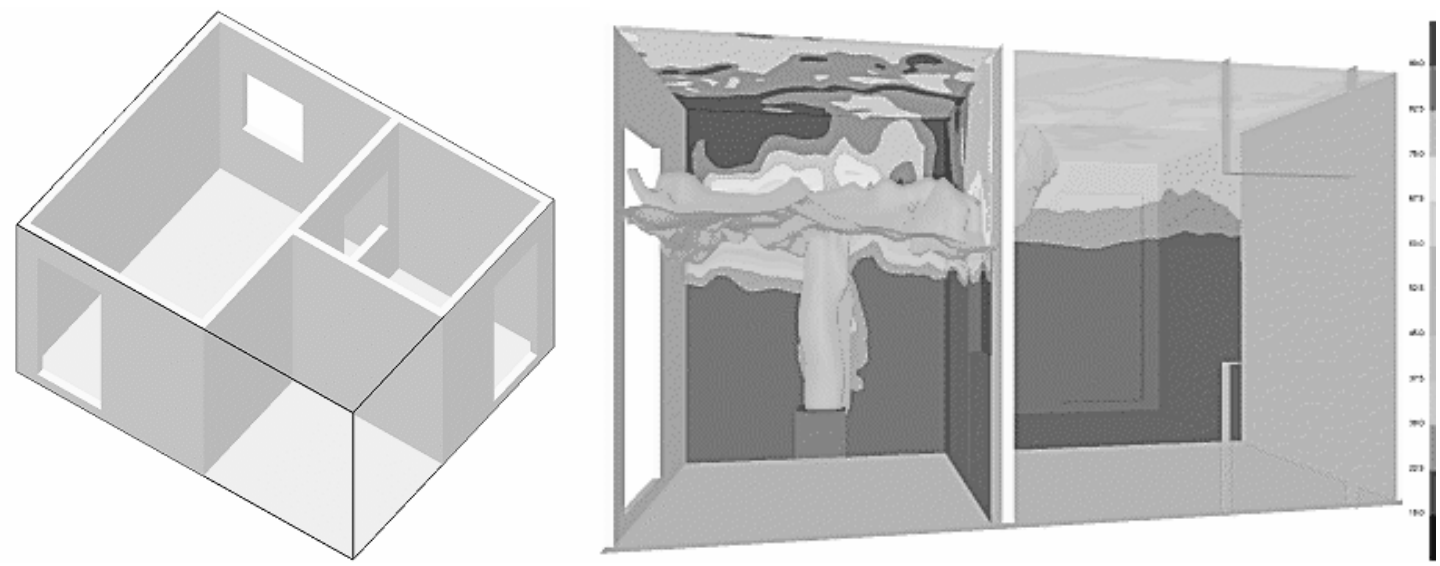

Fig. 9. Test case building viewed in SmokeView (a) geometrical view; (b) fire simulation view.

\section{CONTINUED DEVELOPMENT ON IFCSTEP-FDS}

A set of test case models have been constructed using Autodesk's Revit BIM authoring application to further verify the mapping implementation in ifcSTEP Parser and the ifcSTEP-FDS conversion tool [17]. The test case models created were all single storey buildings ranging from a single ISO9705 room and tworoom models with various internal wall and wall opening configurations to a relatively complex multi-room model having many doors and windows with different opening directions (Fig. 10). Further work has also been carried out to examine the IFC output from an alternative commercial BIM authoring application, ArchiCAD 9.0, with similar results to those shown here.

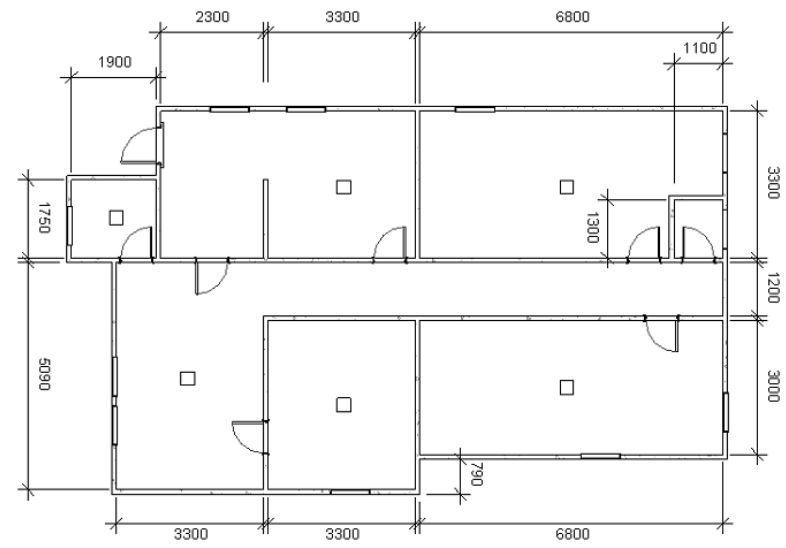

(a)

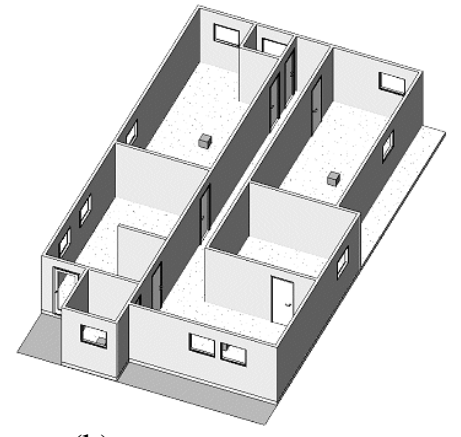

(b)

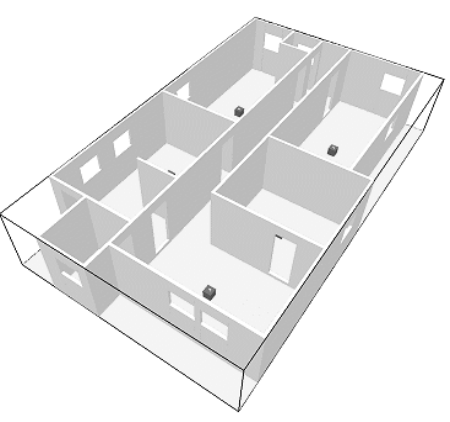

(c)

Fig. 10. Multi-room model (a) floor plan; (b) Revit Building 9 3D view; (c) FDS output in Smokeview. 
ifcSTEP-FDS was originally developed for compatibility with FDS version 4. Since then, subsequent development work has taken place to upgrade the tool for compatibility with the current version of FDS 5. There are a number of areas where the input requirements for FDS 5 are different to that of the earlier versions. The most significant changes include the revised computational mesh definition and the multilayered material specification for all solid boundaries [10]. The subsequent development work has also allowed the physical dimensions and resolution of the computational mesh to be automatically calculated and optimised based on the size of the model. A new set of default surface and material properties have also been incorporated.

\section{CONCLUSION}

The research work described in this paper has successfully implemented a data mapping extension to a fire engineering IFC model parser and also developed a web-based FDS conversion tool as an example application. These tools have successfully converted a set of single storey building models created in Revit Building 9 and ArchiCAD 9 to FDS input data. Given the complexity of the IFC data model and the variants in the current BIM methods and data interoperability standards, the data mapping implementation is currently limited to basic building geometry and suggestions for future work are given elsewhere [16].

While there has been a growing interest in the other domains in the AEC/FM industry to use the IFC data model, particularly for downstream applications, there is certainly scope for the fire engineering domain to benefit from this. The method of sharing building information using IFC open standard data model as described in this paper should be applicable to FDS as well as all other computer models used in the industry whether they be for fire and smoke spread, structural performance or people movement applications. It would also be expected that these computer models may evolve closer to the data structures of the standard data models as they become more widely used and established to reduce the effort of mapping between schema and take advantage of internationally derived structures. For example, it is understood that the new data structures in FDS 5 were designed, in part, to make use of standardised material databases.

The initiatives taken by the fire engineering parser tool and subsequent developments of interface applications for various computer models used by fire engineers would potentially provide a considerable cost saving and improvement on the quality of data exchanged for fire simulations and fire safety design in general.

\section{ACKNOWLEDGEMENTS}

The primary author wishes to thank the IAFSS for the 2008 Excellence in Research Award for the Asia and Australasia region and the invitation to attend the $9^{\text {th }}$ IAFSS International Symposium in Karlsruhe, Germany. The research work described in this paper was undertaken as part of the Masters of Engineering in Fire Engineering programme at the University of Canterbury, which is supported through funding from the New Zealand Fire Service Commission.

\section{REFERENCES}

[1] Gallaher, M. P., O’Connor A. C., Dettbarn J. L., Gilday L. T., “Cost Analysis of Inadequate Interoperability in the US Capital Facilities Industry," National Institute of Standards and Technology Report NIST GCR 04-867, USA, 2004.

[2] ISO 10303-21, "Industrial Automation System - Exchange of Product Model Data - Part 21: Implementation Methods; Clear Text Encoding of the Exchange Structure," International Organization for Standardization, 2002.

[3] Facilities Information Council, “Automated Code Compliance Checking (AC3),” A National Building Information Model Standard Project Fact Sheet, National Institute of Building Sciences, USA, 2007.

[4] Liebich, T., Adachi, Y., Forrester, J., Hyvarinen, J., Karstila, K., Wix, J., "Industry Foundation Classes IFC2x Edition 3”, Model Support Group of the International Alliance for Interoperability, IAI International Council Limited, 2006. 
[5] ISO 10303-11:1994. Industrial automation systems and integration - Product data representation and exchange - Part 11: Description methods: The EXPRESS language reference manual, 1994.

[6] Nisbet, N., Liebich, T., “ifcXML Implementation Guide”, Version 1.0, Modeling Support Group, International Alliance for Interoperability, 2005.

[7] Mowrer, F. W., Williamson, R. B., "Room Fire Modeling Within A Computer-aided Design Framework," Fire Safety Science - Proceedings of the Second International Symposium, Hemisphere Publishing Corp., 1989, pp. 453-462. doi:10.3801/IAFSS.FSS.2-453

[8] Facilities Information Council, "Developing the National Building Information Model Standard," National Institute of Building Sciences, USA, 2006, 1 p.

[9] Amor, R., Jiang, Y., Chen, X., "BIM in 2007 - are we there yet?," CIB $24^{\text {th }}$ W78 Conference Maribor 2007, pp.159-162.

[10] McGrattan, K., Klein, B., Hostikka, S., Floyd, J., "Fire Dynamics Simulator (Version 5) User’s Guide,” National Institute of Standards and Technology Special Publication 1019-5, Gaithersburg Maryland, USA, 2007.

[11] Wade, C. A., A user's guide to BRANZFIRE 2003. Building Research Association of New Zealand, Judgeford, Porirua City, New Zealand, 2003.

[12] Spearpoint M. J., Dimyadi J. A. W., Sharing fire engineering simulation data using the IFC building information model, MODSIM07, International Congress on Modelling and Simulation, Christchurch, 10-13 December 2007.

[13] Sheppard, D., "DXF2FDS Documentation”, National Institute of Standards and Technology, 2006., 2 p

[14] Spearpoint, M., Transfer of Architectural Data from the IFC Building Product Model to a Fire Simulation Software Tool, Journal of Fire Protection Engineering Vol 17 No. 4, 2007, pp.271-292. doi:10.1177/1042391507074681

[15] SECOM Co. Ltd., "IFCsvr ActiveX Component Object Reference”, SECOM Intelligent Systems Lab, 2005.

[16] Dimyadi, J. A. W., "Generating FDS Fire Simulation Input using IFC-based Building Information Model,” Fire Engineering Research Report 07/1 (ISSN 1173-5996), University of Canterbury, New Zealand, 2007, 98 p.

[17] Dimyadi, J. A. W., Spearpoint, M., Amor, R., Generating fire dynamics simulator geometrical input using an IFC-based building information model, ITcon Vol. 12, 2007, pp.443-457.

[18] Thunderhead Engineering Consultants, "PyroSim User Manual (2006.2)", Thunderhead Engineering Consultants in collaboration with The RJA Group Incorporated, 2006. 